\title{
Cadaveric Study of Anatomical Variations in the Musculocutaneous Nerve and in the Median Nerve
}

\author{
Abhilasha Priya1॰ Chandni Gupta ${ }^{2}$ Antony Sylvan D'souza ${ }^{3}$ \\ ${ }^{1}$ Department of Anatomy, School of Medical Sciences, Sharda \\ University, Greater Noida, Uttar Pradesh, India \\ 2 Department of Anatomy, Kasturba Medical College, Manipal, Udupi, \\ Karnataka, India \\ Address for correspondence Abhilasha Priya, MBBS, MD, Department \\ of Anatomy, School of Medical Sciences and Research, Sharda \\ University, Knowledge Park 3, Greater Noida, UP 201310, India \\ (e-mail: abhilasha.priya@sharda.ac.in; dr.abhilashapriya@gmail.com).
}

${ }^{3}$ Department of Anatomy, Wayanad Institute of Medical Sciences, Wayanad, Kerala, India

J Morphol Sci 2019;36:122-125.

\begin{abstract}
Keywords

- communication

- lateral cord

- macroscopic human anatomy

- median nerve

- musculocutaneous nerve

Introduction The musculocutaneous nerve and the median nerve are branches from the lateral cord of the brachial plexus with a root value of $\mathrm{C} 5, \mathrm{C} 6$, and $\mathrm{C} 7$. The medial root of the median nerve is a branch of the medial cord. The present study aims at observing any variations in these peripheral nerves, so that this knowledge can be utilized by surgeons, anesthesiologists, and orthopedicians during surgical procedures and nerve block.

Materials and Methods The present study was carried on 30 adult embalmed cadavers (60 upper limbs) in the department of anatomy of the Kasturba Medical College , Manipal, India. The infraclavicular part of the brachial plexus was dissected, and any anatomical variations in the formation and in the branching pattern of the musculocutaneous nerve and of the median nerve were noted and photographs were taken.

Results The median nerve was noted to be formed from 3 roots in 8 out of 60 dissected upper limbs (13.33\%). The musculocutaneous nerve was absent in $5 \%$ of the dissected limbs, and communications between these 2 nerves were noted in $13.33 \%$ of the dissected limbs.

Conclusions Noted variations of the nerves may be of help to surgeons operating in the axillas and in the arms.
\end{abstract}

\section{Introduction}

The brachial plexus is formed by the ventral rami of the lower four cervical nerves and by the first thoracic nerve, and it supplies the upper limbs. C5, C6, C7, C8 and T1 roots unite to form trunks (upper, middle, and lower) that divide into anterior and posterior divisions. The anterior divisions of the upper

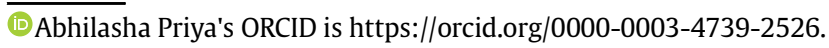

and middle trunks unite to form the lateral cord, which lies laterally to the axillary artery. The musculocutaneous nerve is a continuation of the lateral cord and leaves the axilla by piercing the coracobrachialis muscle. It supplies all of the muscles of the anterior compartment of the arm and continues as a lateral cutaneous nerve of the forearm. The median nerve is formed by two roots; the medial root of the median nerve from the medial cord, and the lateral root of the median nerve from the lateral cord. Both roots join to form received

July 24,2018

accepted

March 28, 2019
DOI https://doi.org/

$10.1055 / \mathrm{s}-0039-1688799$.

ISSN 2177-0298.
Copyright $\odot 2019$ by Thieme Revinter

Publicações Ltda, Rio de Janeiro, Brazil
License terms

(c) $(1) \$$ 
the median nerve in front of the third part of the axillary artery. The median nerve crosses the brachial artery from the lateral to the medial side in the middle of the arm and does not originate any branches in the arm. In the literature, various anatomical variations were described by many authors. The knowledge regarding these variations can serve as a useful guide for surgeons operating in the axillas and in the arms. ${ }^{1}$

\section{Materials and Methods}

The present study was conducted on 60 upper limbs dissected in the anatomy department of the Kasturba Medical College, Manipal, India, over a period of 2 years. The cadavers were embalmed and preserved in a weak formalin solution. The infraclavicular part of the brachial plexus was dissected according to the guidelines of the Cunningham's manual of Practical Anatomy. ${ }^{2}$ During the dissection, the normal pattern, as well as variations from the normal pattern, were noted and photographed. The number of the variations was noted and the result was tabulated using a regular statistics method. The study was started after obtaining the Institutional Ethical Clearance. Any variations from normal was noted and tabulated ( $\mathbf{- T a b l e} \mathbf{1}$ ).

\section{Results}

1) Formation of the median nerve by three roots was seen in 8 out of 60 cases. Out of the three roots of median nerve, two roots was given by the lateral cord of the brachial plexus and one root was given by the lateral cord of brachial plexus as seen in -Figure 1.

2) Absence of the musculocutaneous nerve was seen in 3 out of 60 cases (5\%). In the absence of the musculocutaneous nerve, the muscles of the anterior compartment of the arm were innervated by the median nerve as seen in - Figure 2.

3) Communication between the median and the musculocutaneous nerves was seen in 8 specimens out of 60 (13.33\%). There was a case in which the formation of the median nerve by three roots as well as communication between the median and the musculocutaneous nerve was observed, as seen in - Figure 3.

\section{Discussion}

Variations of the lateral cord are not rare and have been reported by many authors in the past, such as Venieratos et al, ${ }^{3}$ Beheiry, ${ }^{4}$ Budhiraja et al, ${ }^{5}$ and Chitra. ${ }^{6}$ The comparison with similar studies has been shown in - Table 2 . The causes for these anatomical variations in these peripheral nerves are not well understood. It is mentioned that, in humans, the muscles of the upper limbs are derived from the paraxial mesoderm during the $5^{\text {th }}$ week of development. ${ }^{7}$ The axons of the spinal nerves grow toward the mesenchyme. If there is any altered signaling between them, it results in significant variations in the nerve pattern. ${ }^{8}$

Venieratos et $\mathrm{al}^{3}$ described three different types of communications between the musculocutaneous and median nerves in relation to the coracobrachialis muscle. In 16 out of 79 cadavers, 22 communications were found between the musculocutaneous and median nerves. In six subjects, they were present bilaterally. There were three types based on the sites of communications.

Type I: The communication was proximal to the entrance of the musculocutaneous nerve into the coracobrachialis muscle;

Type II: The communication was distal to the coracobrachialis muscle;

Type III: The nerve, as well as the communicating branch, did not pierce the coracobrachialis muscle. Bilateral communications were not necessarily of the same type.

In the present study, the communication between the median nerve and the musculocutaneous nerve was distal to the coracobrachialis muscle.

In the present study, the musculocutaneous nerve was absent in 3 cases out of 60 (5\%). Among these three cases, one case of bilateral absence of musculocutaneous nerve was seen. The coracobrachialis muscle was innervated by a thin branch directly from the lateral cord. The rest of the muscles of the anterior compartment were supplied by the median nerve and, finally, one branch from the median nerve continued as a lateral cutaneous nerve of the forearm. This case was similar to one reported by Beheiry. ${ }^{4}$ There was no communication between the median nerve and the musculocutaneous nerve observed in this case. The third case of absence of musculocutaneous nerve in the present study was seen in the right upper limb of an adult male cadaver. In the absence of the musculocutaneous nerve, all of the muscles of the anterior compartment of the arm were supplied by the median nerve, which later originated a branch that continued as a lateral cutaneous nerve of the forearm. Budhiraja et $\mathrm{al}^{5}$ reported the absence of the musculocutaneous nerve in 13 cases out of 116 (11\%). In the present study, the

Table 1 Showing all the noted variations

\begin{tabular}{|l|l|l|l|}
\hline Specimen number & Observed variations & $\begin{array}{l}\text { Present in number of } \\
\text { dissected upper } \\
\text { limbs }(\boldsymbol{n}=\mathbf{6 0})\end{array}$ & Percentage \\
\hline 1 & Extralateral root of Median nerve & 8 & $13.33 \%$ \\
\hline 3 & Absence of musculocutaneous nerve & 3 & $5 \%$ \\
\hline & $\begin{array}{l}\text { Communication between the } \\
\text { median nerve and } \\
\text { themusculocutaneous nerve }\end{array}$ & 8 & $13.33 \%$ \\
\hline
\end{tabular}


124 Anatomical Variations in Musculocutaneous Nerve and Median Nerve Priya et al.

Table 2 Showing comparison of present study with the other studies done by other authors

\begin{tabular}{|c|c|c|c|c|}
\hline Authors & Sample size & $\begin{array}{l}\text { Absent } \\
\text { musculocutaneous } \\
\text { nerve }\end{array}$ & $\begin{array}{l}\text { Innervation to muscles } \\
\text { of anterior compartment } \\
\text { of the arm }\end{array}$ & $\begin{array}{l}\text { Communiction } \\
\text { between the } \\
\text { median nerve and the } \\
\text { musculocutaneous } \\
\text { nerve }\end{array}$ \\
\hline Beheiry $^{4}$ & 60 & $1.66 \%$ & $\begin{array}{l}\text { Median nerve except cor- } \\
\text { acobrachialis which is } \\
\text { supplied by direct branch } \\
\text { of lateral cord }\end{array}$ & $5 \%$ \\
\hline Chitra $^{6}$ & 50 & - & - & $26 \%$ \\
\hline Joshi $^{13}$ & 170 & $5.5 \%$ & $\begin{array}{l}\text { Median nerve except cor- } \\
\text { acobrachialis which is } \\
\text { supplied by direct branch } \\
\text { of lateral cord }\end{array}$ & $14 \%$ \\
\hline 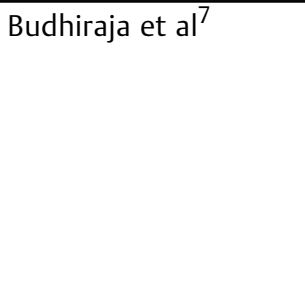 & 116 & $11 \%$ & $\begin{array}{l}\text { Median Nerve supplying } \\
\text { all muscles of anterior } \\
\text { compartment of arm in } \\
\text { absence of musculocuta- } \\
\text { neous nerve except cora- } \\
\text { cobrachialis which is } \\
\text { supplied by direct branch } \\
\text { of lateral cord }\end{array}$ & $26.7 \%$ \\
\hline Dahiphale et al ${ }^{11}$ & 40 & - & - & $25 \%$ \\
\hline Balachandra et al ${ }^{17}$ & 20 & - & - & $5 \%$ \\
\hline Sah SK et al ${ }^{9}$ & 26 & $19 . .23 \%$ & - & - \\
\hline Naveen Kumar et al ${ }^{10}$ & 70 & $3 \%$ & - & - \\
\hline Present Study & 60 & $5 \%$ & $\begin{array}{l}\text { In absence of musculocu- } \\
\text { taneous nerve all muscles } \\
\text { were supplied by median } \\
\text { nerve and not by any } \\
\text { direct branch from lateral } \\
\text { cord }\end{array}$ & $13.33 \%$ \\
\hline
\end{tabular}

musculocutaneous nerve was seen piercing the coracobrachialis muscle in all of the cases in which it was present.

Communication between the median and the musculocutaneous nerves was observed in 8 cases out of 60 (13.33\%). Among these noted communications, five were seen on the left side, and three on the right side. In 1 case out of 60 commu-

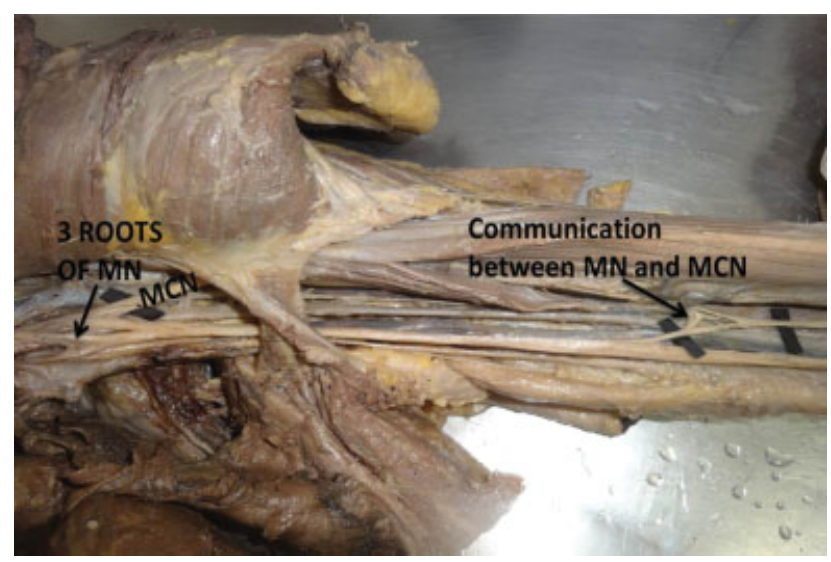

Fig. 1 Three roots of the median nerve with communication between the median nerve $(\mathrm{MN})$ and the musculocutaneous nerve (MCN). nications between the median and the musculocutaneous nerves was seen on both arms of an adult male cadaver. According to the studies of Beheiry, ${ }^{4}$ Budhiraja et al, ${ }^{5}$ Dahiphale et al., ${ }^{11}$ Chitra, ${ }^{6}$ and Choi et al., ${ }^{12}$ communications between the median and the musculocutaneous nerves was seen in $5 \%$ of the cases, in $20.7 \%$ of the cases, in $25 \%$ of the cases,

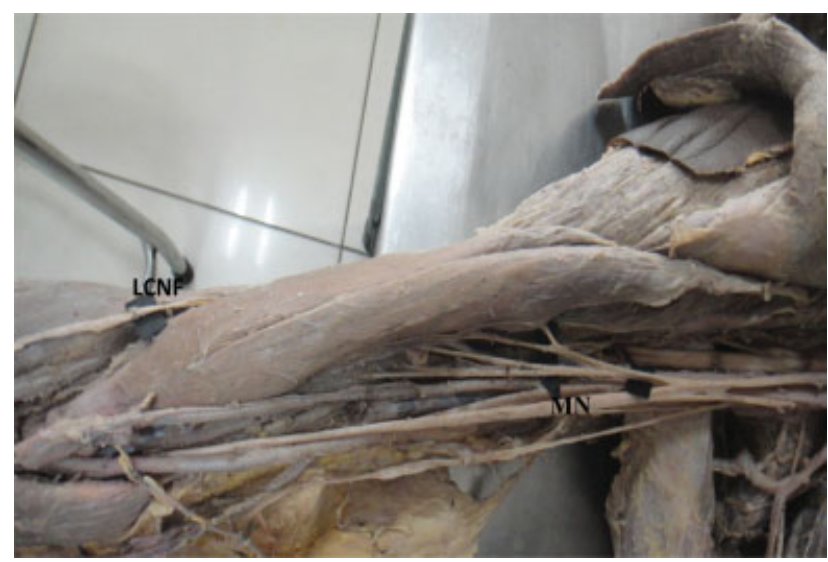

Fig. 2 Absence of musculocutaneous nerve and muscles of the anterior compartment of the arm supplied by the median nerve. Abbreviations: LCNF, lateral cutaneous nerve of the forearm; MN, median nerve. 


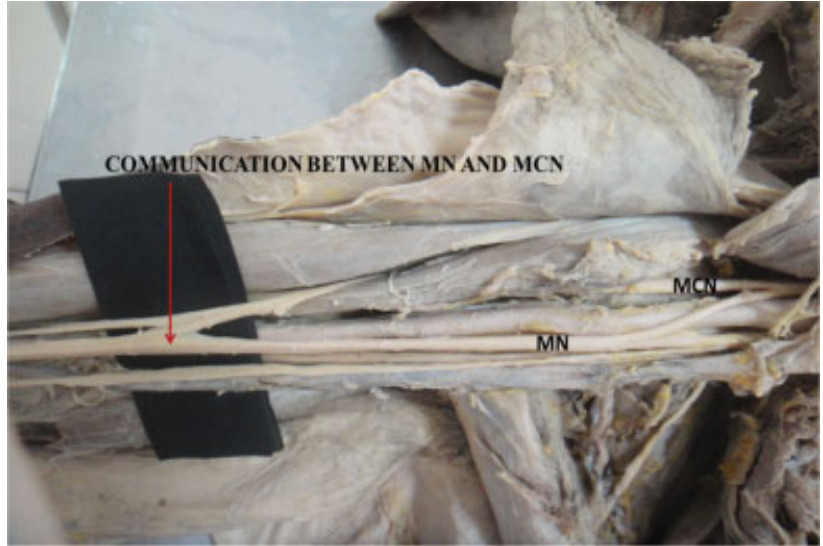

Fig. 3 Communication between the median nerve (MN) and the musculocutaneous nerve( $\mathrm{MCN})$. Absence of musculocutaneous nerve. Median nerve supplying all of the muscles of the anterior compartment of the arm.

in $26 \%$ of the cases, and in $46.4 \%$ of the cases, respectively. Joshi et $\mathrm{al}^{13}$ reported absence of the musculocutaneous nerve in $5.5 \%$ of the cases, and communication between the median and musculocutaneous nerves was noted in $14 \%$ of the cases. The result of the present study is related very closely to this study. In the present study, the communication between the median and the musculocutaneous nerves was more common on the left side, as seen in the study by Choi et al. ${ }^{12}$

In the present study, formation of the median nerve by three roots was noted in 8 out of 60 cases (13.33\%). In all of these cases, two roots were coming from the lateral cord, and one root from the medial cord (four on the left side and four on the right side). In one case, there was also communication between the median and the musculocutaneous nerves. A similar case of formation of the median nerve by three roots was described by Sargon et al., ${ }^{14}$ Saeed et al., ${ }^{15}$ and by Das et al. ${ }^{16}$; with two roots from the lateral cord and one from the medial cord. Balachandra et al (2015) observed 3 roots of the median nerve in $5 \%$ of the cases with absence of the musculocutaneous nerve. ${ }^{17}$

The variations reported in the present study are of importance to surgeons during arthroscopic shoulder reconstructive surgery, nerve block, and in any surgery performed for pathologies involving the coracobrachialis muscles. Knowledge regarding these nerve variations may also be of use in case of treatment for fractures of the midshaft of the humerus. Chances of damage to these nerves can be due to trauma, to tractions, and to compression. It is observed that variant nerves are more prone to compression neuropathy. The knowledge of these variations also helps in correlating particular clinical manifestations with the involved nerve damage. In patients of breast carcinoma undergoing mastectomy, the coracobrachialis muscle is used as a flap to cover the defect after the mastectomy. Therefore, it becomes important to have knowledge regarding the normal anatomy as well as any observed variations in the muscle. ${ }^{18}$

\section{Conflicts of Interests}

The authors have no conflicts of interests to declare.

\section{References}

1 Maheria PB, Chinna NG, Khubchandani PR, et al. A Study of Anatomical Variations of the musculocutaneous nerve. Int J Res Med 2013;2(02):1-4

2 Romanes GJ. Cunningham's Manual of Practical Anatomy. Vol 1. 15th edition. London: Oxford University; 1986

3 Venieratos D, Anagnostopoulou S. Classification of communications between the musculocutaneous and median nerves. Clin Anat 1998;11(05):327-331

4 Beheiry EE. Anatomical variations of the median nerve distribution and communication in the arm. Folia Morphol (Warsz) 2004; 63(03):313-318

5 Budhiraja V, Rastogi R, Asthana AK. Anatomical variations of median nerve formation: embryological and clinical correlation. J Morphol Sci. 2011;28(04):283-286

6 Chitra R. Various types of intercommunications between musculocutaneous and median nerve: An analytical study. Ann Indian Acad Neurol 2007;10:100-104

7 Larsen WJ. Human Embryology. 12th edition. Edinburg: Churchil Livingstone; 1997

8 Le Minor JM. A rare variation of the median and musculocutaneous nerves in man. Arch Anat Histol Embryol 1990; 73:33-42

9 Sah SK, Chaudhary D, Pandey N. Prevalence of Absence of Musculocutaneous Nerve among Nepalese Cadaver. Int Journal of Scientific and Research Publication 2016;6(08):222-225

10 Kumar Naveen B, Sirisha V, Kumar Udaya P, Kalpana T. The formation of lateral cord of Brachial Plexus and it's Branches- A Cadaveric Study. Int J. Anat Res 2018;6(1.1):4836-4839

11 Dahiphale VP, Porwal SS, Joshi DS. Variations in the infraclavicular part of brachial plexus- a dissection study. Anatomica Karnataka 2012;6(01):62-65

12 Choi D, Rodríguez-Niedenführ M, Vázquez T, Parkin I, Sañudo JR. Patterns of connections between the musculocutaneous and median nerves in the axilla and arm. Clin Anat 2002;15(01): 11-17

13 Joshi SD, Joshi SS, Athavale SA. Hitch hiking fibres of lateral cord of brachial plexus and the median nerve in search of their destination. J Anat Soc India 2008;57(01):26-29

14 Sargon MF, Uslu SS, Celik HH, Akşit D. A variation of the median nerve at the level of brachial plexus. Bull Assoc Anat (Nancy) 1995;79(246):25-26

15 Saeed M, Rufai AA. Median and musculocutaneous nerves: variant formation and distribution. Clin Anat 2003;16(05): 453-457

16 Das S, Paul S. Anomalous Branching Pattern of Lateral Cord of Brachial Plexus. Int J Morphol 2005;23(04):289-292

17 Balachandra N, Kulkarni V, BR Ramesh. Absence of musculocutaneous nerve- a study of its incidence and clinical implications. International Journal of Basic and Applied Medical Sciences. 2015;5(01):42-47

18 Butz JJ, Shiwlochan DG, Brown KC, Prasad AM, Murlimanju BV, Viswanath S. Bilateral variations of brachial plexus involving the median nerve and lateral cord: An anatomical case study with clinical implications. Australian Medical J 2014;7(05): 227-231 